\title{
Discussion Regarding Sources and Ages of Groundwater in Southeastern California
}

\author{
M.L. Davisson
}

March 3, 2000

U.S. Department of Energy

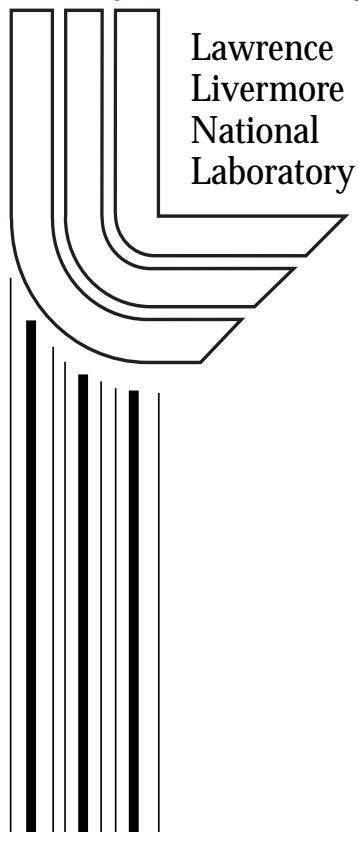




\section{DISCLAIMER}

This document was prepared as an account of work sponsored by an agency of the United States Government. Neither the United States Government nor the University of California nor any of their employees, makes any warranty, express or implied, or assumes any legal liability or responsibility for the accuracy, completeness, or usefulness of any information, apparatus, product, or process disclosed, or represents that its use would not infringe privately owned rights. Reference herein to any specific commercial product, process, or service by trade name, trademark, manufacturer, or otherwise, does not necessarily constitute or imply its endorsement, recommendation, or favoring by the United States Government or the University of California. The views and opinions of authors expressed herein do not necessarily state or reflect those of the United States Government or the University of California, and shall not be used for advertising or product endorsement purposes.

Work performed under the auspices of the U. S. Department of Energy by the University of California Lawrence Livermore National Laboratory under Contract W-7405-Eng-48.

This report has been reproduced directly from the best available copy.

Available to DOE and DOE contractors from the

Office of Scientific and Technical Information

P.O. Box 62, Oak Ridge, TN 37831

Prices available from (423) 576-8401

http://apollo.osti.gov/bridge/

Available to the public from the National Technical Information Service

U.S. Department of Commerce 5285 Port Royal Rd., Springfield, VA 22161 http://www.ntis.gov/

OR

Lawrence Livermore National Laboratory Technical Information Department's Digital Library http://www.llnl.gov/tid/Library.html 
Discussion Regarding Sources and Ages of Groundwater in Southeastern California

\author{
M. Lee Davisson \\ Health and Ecological Assessment Division \\ Lawrence Livermore National Laboratory
}

March 3, 2000 



\section{Introduction}

A planned groundwater storage project for future drought relief has been assessed in the Fenner Gap area of the Fenner, Cadiz, and Bristol watershed region of southeastern California.

Questions regarding the source and age of groundwater beneath the proposed project area were resolved using natural isotope abundances measured at LLNL. The following presents data (Table 1), briefly summarizes conclusions of that data, and records correspondance with the sponsor Geosciences Support Services Inc.

\section{Groundwater Sources}

The deuterium and oxygen-18 data were measured as a ratio to the more abundant isotope hydrogen and oxygen-16, respectively. The measured ratio is normalized to Standard Mean Ocean Water, which is the internationally recognized standard, and converted to parts per thousand deviation from this standard, known as a "del $(\delta)$ value. The $\delta \mathrm{D}$ and $\delta^{18} \mathrm{O}$ values have minimal differences among the Fenner Gap groundwater, indicating that all groundwater collected is either from the same source or that the aquifer water in this region is well mixed. The absolute value of the $\delta \mathrm{D}$ and $\delta^{18} \mathrm{O}$ is proportional to the elevation (temperature) of the recharge area. This is due to a well-known isotope depletion effect in precipitation caused by increasing elevation and decreasing air temperature. The $\delta \mathrm{D}$ and $\delta^{18} \mathrm{O}$ values of mean annual precipitation have been documented in southeastern California by Irving Friedman and others (1992). The site closest to your field area monitored by Friedman and others is at Mitchell Caverns, at approximately 4000 feet located several miles to the north. The mean annual $\delta \mathrm{D}$ value of precipitation at this site was -74 per mil (winter average was -82 , and summer -67 ). This compares favorably with the groundwater values measured ( -78 to -80 per mil), suggesting a mean recharge elevation for the groundwater of around 4000 feet. An additional conclusion from this data is that since the $\delta \mathrm{D}$ and $\delta^{18} \mathrm{O}$ values reflect the same values observed in modern precipitation. This suggests that the groundwater is of Holocene age $(<10,000$ years old). This assumes that during the Pleistocene the isotope values of mean annual precipitation were lower than today due to global cooling.

The $\delta \mathrm{D}$ and $\delta^{18} \mathrm{O}$ data can also be compared on a cross-plot. A well established linearity between $\delta \mathrm{D}$ and $\delta^{18} \mathrm{O}$ in precipitation forms a line known as the Meteoric Water Line (MWL), which has a characteristic slope of 8 and a y-intercept of 10 (see Craig, 1961). Almost all precipitation originating from the Pacific Ocean have isotopic values lying essentially on the MWL. As condensed precipitation evaporates (i.e. in a lake or vadose zone), the $\delta \mathrm{D}$ and $\delta^{18} \mathrm{O}$ value plots progressively to the right of the MWL. The groundwater isotopic values measured for your study plot very close to the MWL, suggesting almost no evaporation had occurred during recharge.

\section{Groundwater Ages}

Radiocarbon $\left({ }^{14} \mathrm{C}\right)$ was measured on the dissolved inorganic carbon (DIC) in the Fenner Gap groundwater. ${ }^{14} \mathrm{C}$ is radioactive and decays at a slow, constant rate, having a half-life of 5730 years. This half-life is ideal for dating old groundwater. ${ }^{14} \mathrm{C}$ is produced naturally in the upper atmosphere at a low concentration $\left(10^{-12}{ }^{14} \mathrm{C}\right.$ atoms for every $\left.{ }^{12} \mathrm{C}\right)$. Surface testing of nuclear weapons in the late 1950's and early 1960's doubled the inventory of ${ }^{14} \mathrm{C}$ in the atmosphere, and has been slowly returning to normal levels since. The ${ }^{14} \mathrm{C}$ data is presented as a percent of modern carbon (pmc), which is a ${ }^{14} \mathrm{C} /{ }^{12} \mathrm{C}$ ratio normalized to the ${ }^{14} \mathrm{C} /{ }^{12} \mathrm{C}$ ratio of atmospheric $\mathrm{CO}_{2}$ in 1950 , multiplied by 100 . In a pure system a ${ }^{14} \mathrm{C}$ content of $\leq 100 \mathrm{pmc}$ is equivalent to an 
age prior to 1950 , while a content $\geq 100$ pmc represents a more recent age, which has incorporated nuclear bomb produced ${ }^{14} \mathrm{C}$.

The four groundwaters measured show similar ${ }^{14} \mathrm{C}$ contents (18 to $25 \mathrm{pmc}$ ), and have an apparent age range of 14,000 to 11,500 years old. The apparent age is calculated directly from the measured ${ }^{14} \mathrm{C}$ and doesn't account for any ${ }^{14} \mathrm{C}$-absent carbon added to the DIC by water-rock interaction. Assuming that the groundwater is not a mixture of older and younger groundwater, the apparent ages represent maximum subsurface residence times. Calculating "true" ages for these groundwaters would require knowing the amount of ${ }^{14} \mathrm{C}$-absent carbon that was dissolved in the groundwater during and after recharge. The database is not extensive enough to calculate these ages. It has been recognized in many groundwater basins that typically $15-20 \%$ of the DIC in groundwater originated from ${ }^{14} \mathrm{C}$-absent sources, most likely incorporated during recharge. However, the potential amount of ${ }^{14} \mathrm{C}$-absent DIC incorporated during recharge is $0-50 \%$. Taking this into account, in general the groundwater ages are probably early Holocene to late Pleistocene in age. Given that the $\delta \mathrm{D}$ and $\delta^{18} \mathrm{O}$ values of these groundwaters are consistent with modern precipitation values, the groundwater ages are more likely early Holocene in age.

The database also includes $\delta^{13} \mathrm{C}$ values, which are the ${ }^{13} \mathrm{C} /{ }^{12} \mathrm{C}$ ratios normalized to a recognized standard. The values are typical for groundwater, which can range from 0 to -20 per mil. The potential sources contributing to the $\delta^{13} \mathrm{C}$ values are 1) soil zone $\mathrm{CO}_{2}$ respired by plants $(-28$ per mil for $\mathrm{C} 3$ plants; -13 per mil for $\mathrm{C} 4$ plants), 2) atmospheric $\mathrm{CO}_{2}(-8.0$ per mil), and 3) dissolved carbonate minerals in the subsurface ( 0 to -10 per mil). The contribution from each of these sources to the Fenner Gap groundwater cannot be discerned due to the lack of data.

The tritium $\left({ }^{3} \mathrm{H}\right)$ analyses of the groundwater indicate that no measurable tritium is present in these samples. ${ }^{3} \mathrm{H}$ is a rare isotope of hydrogen that is naturally produced in the upper atmosphere. Surface testing of nuclear weapons also increased the inventory of ${ }^{3} \mathrm{H}$ in the atmosphere. Almost all observable ${ }^{3} \mathrm{H}$ today in environmental samples is residual from the testing era. ${ }^{3} \mathrm{H}$ has a short half-life of 12.43 years, making it ideal for age dating of young groundwater. The data are presented as a radioactivity measurement of picocuries per liter of water ( $\mathrm{pCi} / \mathrm{L})$. One tritium unit (TU) is equivalent to $3.2 \mathrm{pCi} / \mathrm{L}$. The amount of ${ }^{3} \mathrm{H}$ expected in modern rainfall in southern California is around 10TU. This amount is significantly lower than precipitation in the early 1960s, which was around 300TU.

\section{Water Quality}

One independent sample (PW-1) was measured for total organic carbon (TOC). The TOC was below the instrument detection limit of 100 parts per billion. This TOC level is typical for old groundwater in oxidized environments, where sedimentary organic matter is low.

\section{Issues in Chloride Mass Balance}

Wet deposition of chloride in southern California. According to Liljestrand and Morgan (1981), wet deposition ranged between 5.0 and $164 \mu \mathrm{eq} / \mathrm{L}(0.177$ to $5.8 \mathrm{mg} / \mathrm{L})$. The lowest was at Wrightwood (San Gabriel Mts.) and the highest in Los Angeles. Big Bear was 5.2 $\mu$ eq/L (0.184 $\mathrm{mg} / \mathrm{L}$ ), although the data only represents 3 months of sample collection in 1979 and probably doesn't represent a statistically significant database. Wrightwood was only 10 months of data collection. For further reference, Riverside was $30 \mu \mathrm{eq} / \mathrm{L}(1.06 \mathrm{mg} / \mathrm{L})$. 
Dettinger (1989) makes references to limited work that collected bulk chloride in the eastern Sierra Nevada. He states that this data is likely skewed to the wet deposition concentration because the manner in which they were sampled. Dettinger (1989) uses $0.6 \mathrm{mg} / \mathrm{L}$ for total chloride deposition for groundwater basins in Nevada.

The chloride mass balance approaches to estimating recharge has many hidden trap doors, since chloride sources and deposition rates are likely complex. For example, one instructive data correlation is the $\delta^{18} \mathrm{O}$ versus the chloride concentration (Fig. 1). These data are from Dan Stephens' report. Note that higher $\delta^{18} \mathrm{O}$ values (lower recharge elevations and/or greater evaporation) have higher chloride concentrations. The regression is very good $\left(\mathrm{R}^{2}=0.95\right)$, particularly leaving out the Danby well and PAHO. Danby well is an open well casing and is suspect because it may be evaporated, while PAHO is actually in the Orange Blossom Wash south of the Marble Mts. Including these two points in the regression yields $\mathrm{R}^{2}=0.65$.

If we assume that the chloride deposition is constant throughout the Fenner basin, then the $\delta^{18} \mathrm{O}$ chloride correlation suggests that higher elevation recharge (lower $\delta^{18} \mathrm{O}$ ) has less total evaporation, while lower elevations have higher total evaporation.

However, if we compare the average chloride concentration measured in Fenner groundwater (62.7 mg/L Daniel P. Stephens report) to those in Nevada groundwater (10.2 mg/L; Dettinger, 1989), the Fenner groundwaters are unusually high. This may suggest that either chloride deposition rates are higher (up to six times higher, or $3.6 \mathrm{mg} / \mathrm{L}$ ), or other sources of chloride (rocks?) are dissolved in the groundwater.

One could also argue that the total evaporation is higher in Fenner, and hence the recharge rate is lower. That argument is hard to defend, however, since the climate, lithologies, and basin morphologies of Fenner and Nevada are very similar.

Another important process controlling chloride concentration is mixing. Mixing of groundwater occurs in the Fenner Gap, as indicated by the stable isotope results (Fig. 2). Since the chloride concentration of recharge decreases with increasing recharge (i.e. $\delta^{18} \mathrm{O}-\mathrm{Cl}$ plot), then mixing between low elevation and high elevation recharge sources in Fenner Gap skews the chloride toward the low elevation concentration. This mixed chloride concentration will yield higher evaporation rates using a chloride mass balance approach, and will result in a lower recharge rate. 
Fig. 1

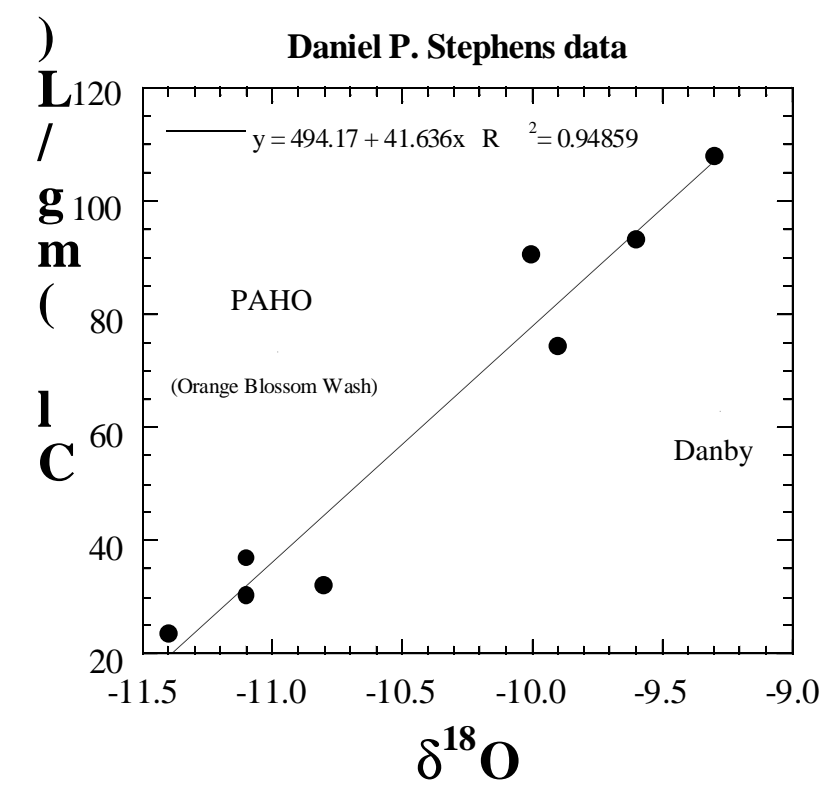

Fig. 2

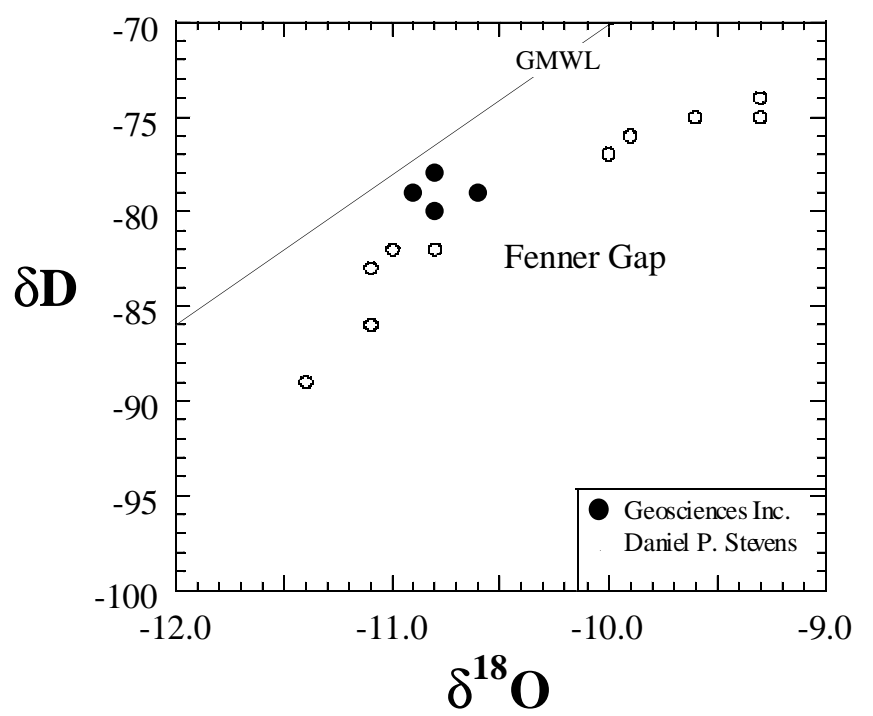

\section{Radiocarbon Interpretation Assuming No Mixing (Piston Flow).}

Indicated in figure 1 are the data that LLNL generated and those from Daniel P. Stephens' report. Also illustrated are likely end-member compositions for inorganic carbon sources dissolved in groundwater in the recharge areas (open squares). The ${ }^{14} \mathrm{C}$ values of recharging groundwater can range from 50 to $100 \mathrm{pmc}$. Paleozoic carbonate rock has no ${ }^{14} \mathrm{C}$ and likely a high $\delta^{13} \mathrm{C}$ value.

Reaction of recharging water with the Paleozoic carbonate results in the lower initial ${ }^{14} \mathrm{C}$. Dashed lines are trajectories for water-rock interaction between the different recharge carbon sources and the Paleozoic carbonate rock. Note that most of the groundwater ${ }^{14} \mathrm{C}$ and $\delta^{13} \mathrm{C}$ values for Fenner Gap groundwater lie slightly to the left of the reaction lines. If they were lying directly on these lines, then we could have invoked a simple water-rock interaction to account for all the ${ }^{14} \mathrm{C}$ depletion relative to a recharge source. However, because they lie slightly to the left of the lines, 
some radioactive decay is suggested. As indicated by the horizontal arrows, an age range from 6518 to 9901 years is calculated. These are the oldest possible ages that can be calculated from these ${ }^{14} \mathrm{C}$ values. However, for these ages, no mixing of groundwater occurs.

\section{Possible Groundwater Ages Assuming Mixing (Dispersive Flow)}

Modeling radiocarbon ages in dispersive flow regimes has not been reported in published scientific literature. Difficulties in interpreting ages stem from tracking the thousands of individual flow lines, determining their transport rates, and following their carbonate equilibrium reactions. This would be difficult with only an observational database. In the Fenner basin, three basic lithologies exist: fractured granitic rock, fractured Paleozoic carbonates, and coarse-grain alluvium. Because of tectonic deformation and juxtaposition of these lithologies, groundwater flow can transcend these different lithological regimes. Each lithology presents a unique environment for carbonate equilibria. For example, a groundwater whose dissolved carbon equilibrates with the Paleozoic carbonate, and subsequently flows into granitic rock would likely precipitate a large portion of its dissolved carbon because it would be in a supersaturated state. This could cause significant shifts in $\delta^{13} \mathrm{C}$ value, but none in ${ }^{14} \mathrm{C}$. As another example, mixing of a groundwater in equilibrium with granitic rock with a groundwater in equilibrium with Paleozoic carbonate, would skew the ${ }^{14} \mathrm{C}$ value of the mixture toward the carbonate groundwater.

Using the various mixing and reaction scenarios for groundwater in the Fenner basin, figure 2 illustrates one in which the ${ }^{14} \mathrm{C}$ values can be interpreted as a mixture of young groundwater. As an example, we can assume that a groundwater originates in the Paleozoic carbonate and resides in there for 1000 years. The resulting ${ }^{14} \mathrm{C}$ value can be as low as $5 \mathrm{pmc}$ (see Fig. 2 and Davisson et al., 1999). If this water were then to flow into a regime dominated by granitic rock, much of the dissolved carbon would precipitate. Figure 2 shows the $\delta^{13} \mathrm{C}$ effect when $80 \%$ of the dissolved carbon precipitates as calcium carbonate under a Rayleigh process. If this $\delta^{13} \mathrm{C}$ modified groundwater were then to mix with a young alluvial groundwater with an initial ${ }^{14} \mathrm{C}$ of $50 \mathrm{pmc}$, then a mixing line can be drawn through the Fenner Gap groundwater. The mixed ages of the Fenner Gap groundwater would only range from 550 to 700 years, even though the ${ }^{14} \mathrm{C}$ values are low.

It is likely that this mixing scenario is not common throughout the basin, however, it may occur in areas where volumetrically significant quantities of groundwater recharge and flow. The example was provided simply to provide a lower limit to possible age interpretations.

\section{Additional Issues}

An important point about the ${ }^{14} \mathrm{C}$ determinations is that they do not necessarily represent an integrated sampling of groundwater flowing beneath the Fenner Gap. The small number of samples collected and measured do not systematically sample at various depths and geographic locations across the gap. Therefore, the ${ }^{14} \mathrm{C}$ values measured could be skewed toward older flow paths.

Based on the $\delta^{18} \mathrm{O}$ and $\delta \mathrm{D}$ of the Fenner Gap wells, mixing with some local or lower elevation recharge is probable. Note that the ${ }^{14} \mathrm{C}$ of the Fenner Gap wells are slightly higher than similar wells in the Fenner Basin listed in the Daniel P. Stephens report. This suggests some younger, more local recharge occurs toward the Fenner Gap. 
Other sources of dissolved carbon cannot be ruled out. For example, magmatic $\mathrm{CO}_{2}$ can be present, and doesn't necessarily need an active volcanic edifice to manifest itself (see Rose and Davisson, 1996). Given the moderate heat flow $\left(100 \mathrm{~mW} / \mathrm{m}^{2}\right)$ and recent volcanic activity for the area, magmatic $\mathrm{CO}_{2}$ cannot be easily discounted, and its presence would reduce the ${ }^{14} \mathrm{C}$ value of groundwater.

\section{References}

Craig, H., 1961, Isotopic variations in meteoric water. Science, 133, 1702-1703.

Davisson, M.L., Smith, D.K., Keneally, J., Rose, T.P., 1999, Isotope hydrology of southern Nevada groundwater: stable isotopes and radiocarbon. Water Resources Research 35, 279294.

Dettinger, M.D., 1989, Reconnaissance estimates of natural recharge to desert basins in Nevada, USA, by using chloride-balance calculations. J. Hydrol. 106, 55-78.

Friedman, I., Smith, G.I., Gleason, J.D., Warden, A., Harris, J.M., 1992, Stable isotope composition of waters in southeastern California. 1. Modern Precipitation. Journal of Geophysical Research, 97, 5795-5812.

Liljestrand, H.M. and Morgan, J.J., 1981, Spatial variations of acid precipitation in southern California. Environ. Sci. Technol., 15, 333-339.

Rose, T.P. and Davisson, M.L., 1996, Radiocarbon in hydrologic systems containing dissolved magmatic carbon dioxide. Science, 273, 1367-1370.

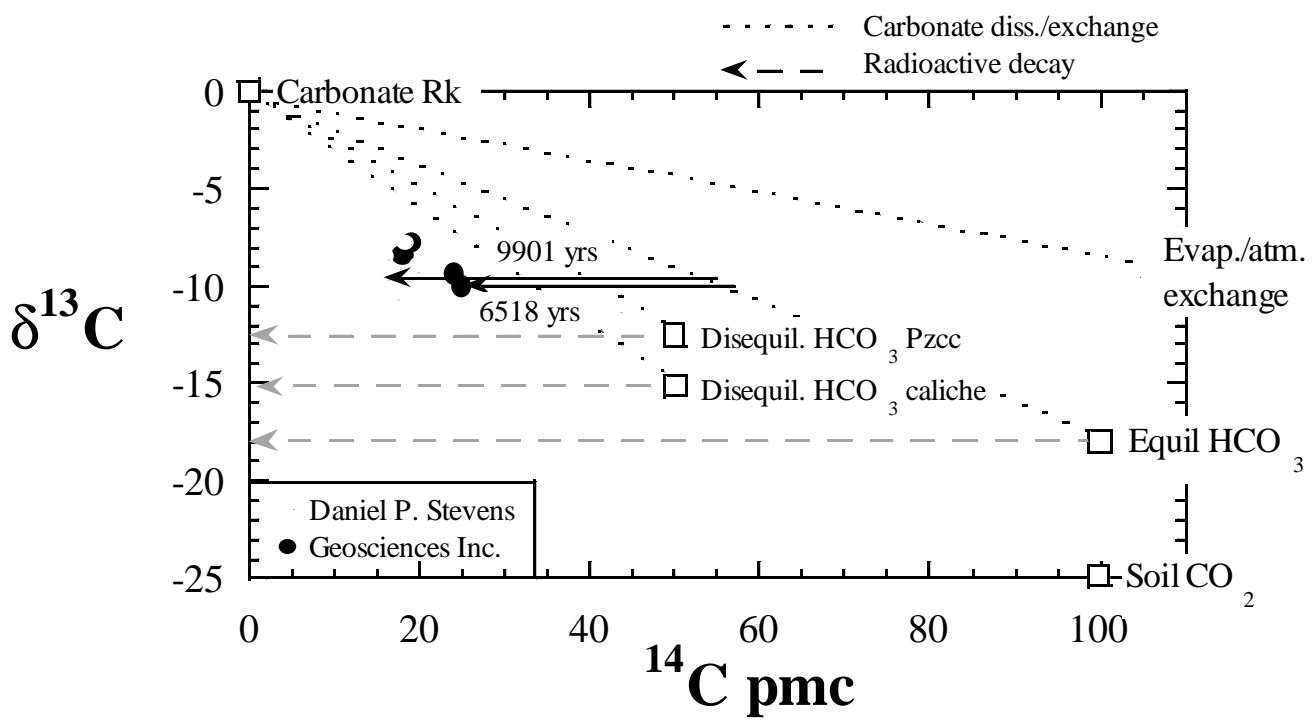

Fig. 1. No Mixing. 


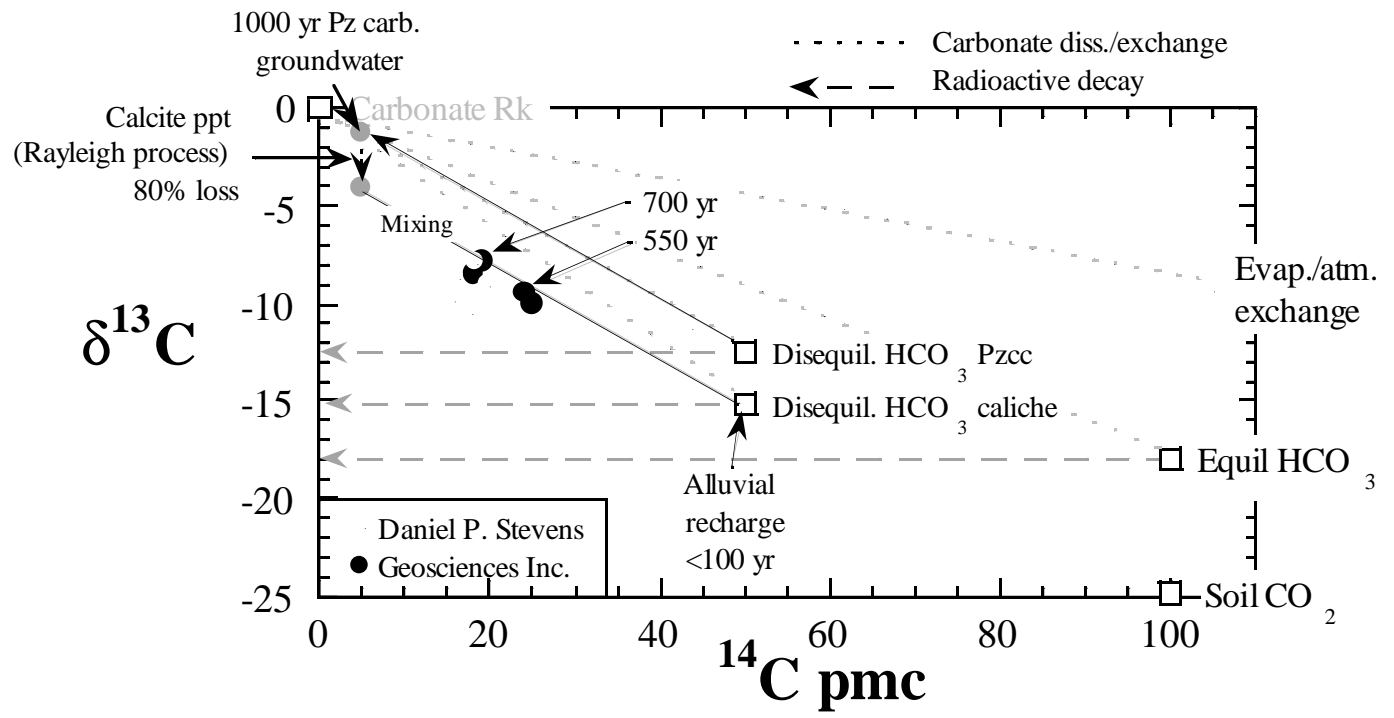

Fig. 2. Possible mixing scenario between young groundwaters resulting in low ${ }^{14} \mathrm{C}$ values. 